\title{
NUTRIENTES NO MANTILHO EM PASTAGEM NATIVA SOB DISTINTOS MANEJOS ${ }^{1}$
}

\author{
LITTER NUTRIENTS IN NATIVE PASTURE SUBMITTED \\ TO DISTINCTS MANAGEMENTS
}

\author{
Ingrid Heringer $^{2}$ Aino Victor Ávila Jacques ${ }^{3}$
}

\section{RESUMO}

A avaliação da quantidade de nutrientes no mantilho é importante para verificar a ciclagem de nutrientes e a preservação da fertilidade do solo. O teor e a quantidade de nutrientes no mantilho e material senescente foram estudados em pastagem nativa sob pastejo, sujeita à queima e manejos alternativos, durante um ano, nos Campos de Cima da Serra, no Rio Grande do Sul. O acúmulo de mantilho foi coletado em gaiolas de exclusão ao pastejo, a cada 90 dias. O mantilho representou o material morto desprendido da planta existente junto à superfície do solo. A esta fração foi adicionado o material senescente ligado à planta. Os tratamentos foram pastagem nativa sob pastejo sem queima e sem roçada há 32 anos, melhorada há sete anos e com queima bienal há mais de 100 anos. $O$ delineamento experimental foi completamente casualizado com três repetições. Os teores de $\mathrm{Ca}$ e Mg no mantilho mais material senescente foram inferiores no tratamento queimado em relação às áreas sem queima. $O$ melhoramento da pastagem aumentou os teores de nutrientes nos tecidos. A quantidade acumulada de nutrientes, reflexo da produção de mantilho e material senescente, foi maior nos sistemas sem queima.

Palavras-chave: pastagem natural, material senescente, macronutrientes, melhoramento.

\section{SUMMARY}

The evaluation of litter nutrient quantity is important to verify nutrient cicling and soil fertility preservation. The content and quantities of nutrients in litter was evaluated in native pasture under grazing, submitted to burning and alternative practices, along one year, in Campos de Cima da Serra region, Rio Grande do Sul State, Brazil. The litter accumulation was evaluated in grazing exclusion cage, every 90 days. The litter represented the dead material detached from plant and present on the soil surface after the forage cutting. To this portion, the dead material still attached to the plant was added. The treatments were natural pasture under grazing: without burning and without mowing for 32 years, improved for seven years and biennial burning for more than 100 years. The experimental design was a completely randomized, with three replications. The biennial burning decreased the concentration of $\mathrm{Ca}$ and $\mathrm{Mg}$ in litter plus senescent material as compared to the systems without burning. The improved treatments increased the nutrient contents in the dead tissues. The tissue nutrient quantity accumulated, as a result of litter plus senescent material production, was high in the systems without burning.

Key words: natural pasture, senescent material, macronutrients, improvement.

\section{INTRODUÇÃO}

A importância de quantificar o material morto em pastagens não se deve somente aos seus efeitos sobre o crescimento da forragem e consumo animal, mas também à sua importância na ciclagem de nutrientes e na preservação do sistema de produção. A composição do material rejeitado no pastejo e que retorna ao solo é um dos aspectos básicos determinantes da manutenção dos níveis de fertilidade e da conservação do solo.

A ciclagem de nutrientes em pastagens, funcionalmente, possui quatro fontes: material morto ligado à planta, resíduos vegetais não incorporados

\footnotetext{
${ }^{1}$ Artigo extraído da Tese de Doutorado apresentada à Universidade Federal do Rio Grande do Sul, pelo primeiro autor, como um dos requisitos para a obtenção do grau de Doutor em Zootecnia. Projeto financiado pelo CNPq.

${ }^{2}$ Zootecnista. Rua Coronel Passos Maia, 1103/103, 89820-000, Xanxerê, SC. E-mail:renato@prezotto.com.br. Autor para correspondência.

${ }^{3}$ Engenheiro Agrônomo, PhD., Professor Titular do Departamento de Plantas Forrageiras e Agrometeorologia, Universidade Federal do Rio Grande do Sul. Pesquisador do CNPq. E-mail:aino@ vortex.ufrgs.br. 
ao solo, resíduos vegetais incorporados ao solo e fezes dos animais (PEARSON \& ISON, 1994). A incorporação de mantilho, juntamente com a ciclagem de raízes, é a mais importante fonte de $\mathrm{N}$ em solos de baixa produtividade (DERNER et $\boldsymbol{a l}$., 1997; TRACY \& FRANK, 1998). O fluxo de N através da atividade microbiana também é intensamente afetado pelo pastejo, sendo que as áreas que sustentarem maior produção animal terão maior reserva de $\mathrm{N}$ no solo. Já a decomposição de resíduos de plantas é controlada principalmente pela disponibilidade de N (MARY et al., 1996; RUSSELLE, 1997), e como muito do N volatilizado durante a queima não é reposto a longo prazo pela fixação (LEY \& D’ANTONIO, 1998), há sérios riscos de empobrecimento do ecossistema.

Em pastagens naturais, o ciclo ecológico natural do $\mathrm{N}$ tende a se manter estável, e o $\mathrm{N}$ utilizado pelas plantas e animais será reciclado como restos vegetais e dejetos animais (BAETHGEN, 1992). A queima, no entanto, perturba esse ciclo ecológico, reduzindo a cobertura do solo e o retorno de restos vegetais, podendo, assim, comprometer a preservação da fertilidade do solo a médio e longo prazos. A maior contribuição de espécies com concentrações relativamente altas de nutrientes também aumenta a qualidade do mantilho e influencia na sua taxa de decomposição (RUSSELLE, 1997). Em função de o regime de queimadas interferir acentuadamente na disponibilidade de material morto e na flora das pastagens (HERINGER, 2000), também poderá ter reflexos na ciclagem de nutrientes e, conseqüentemente, na sustentação da atividade produtiva.

Apesar da importância agronômica e ecológica do material morto na pastagem, são escassos os trabalhos que avaliam a qualidade desta fração. Dentre estes, destaca-se o de ESTIVALET (1997), que, ao estudar os teores de nutrientes na pastagem nativa da Depressão Central, sujeita à queima, ceifa, diferimento e exclusão ao pastejo, observou que somente o conteúdo de $\mathrm{N}$ apresentou tendência de níveis inferiores no material senescente da pastagem queimada. Segundo SACIDO \& CAUHÉPÉ (1998), a queima pode aumentar temporariamente os teores de nutrientes nos tecidos, através da maior oferta de $\mathrm{Ca}, \mathrm{Mg}, \mathrm{P}$ e $\mathrm{K}$ para as plantas, porém estes valores tendem a retornar aos níveis originais imediatamente.

O material morto corresponde ao combustível para queima, pois é muito inflamável, e representa grande reserva de $\mathrm{C}$ e $\mathrm{N}$, que poderão ser perdidos por ocasião da queima. ESTIVALET (1997) verificou, no material morto, quantidade média de $46,6 \mathrm{~kg} \cdot \mathrm{ha}^{-1}$ de $\mathrm{N} ; 4,1 \mathrm{~kg} \cdot \mathrm{ha}^{-1}$ de $\mathrm{P}$; 26,1 kg.ha ${ }^{-1}$ de K; 24,9kg.ha ${ }^{-1}$ de Ca; e 13,0kg.ha ${ }^{-1}$ de $\mathrm{Mg}$. Para todos os nutrientes, as quantidades presentes no material morto acumulado foram inferiores nos tratamentos com queima, alertando sobre as prováveis conseqüências que a queima contínua pode ter em relação à fertilidade do solo e sobre todo o sistema de produção.

Nesse contexto, os objetivos deste trabalho foram avaliar os teores e quantidades de nutrientes presentes no mantilho acrescido do material senescente de uma pastagem nativa conduzida por longo período sob distintos manejos.

\section{MATERIAL E MÉTODOS}

Este estudo foi realizado no município de André da Rocha - RS, na região fisiográfica dos Campos de Cima da Serra, a uma altitude aproximada de $800 \mathrm{~m}$, a $28^{\circ} 38^{\prime}$ de latitude sul e $58^{\circ} 34^{\prime}$ de longitude oeste. O clima é temperado úmido $(\mathrm{Cfb})$, com verões amenos. O solo do local é um Latossolo Vermelho Distroférrico típico, de textura argilosa, que se caracteriza quimicamente pela baixa saturação de bases, deficiência de fósforo (P), teores altos de matéria orgânica e níveis tóxicos de alumínio (HERINGER, 2000). A vegetação natural representa uma zona de transição entre o campo e a mata, com grande cobertura e dominância de gramíneas cespitosas.

O estudo realizou-se sobre três áreas de campo nativo, todas pastejadas e manejadas sob distintos modos, as quais seguem sem queima e sem roçada há 32 anos (SQSQ) melhoradas há sete anos (CNM) e queimadas numa frequiência bienal há mais de 100 anos. O delineamento experimental foi completamente casualizado com três repetições.

A área com sete anos de melhoramento do campo nativo recebeu, em 1990, preparo superficial com grade niveladora, a uma profundidade média de 4 a $5 \mathrm{~cm}$, aplicação superficial de calcário e adubo e a introdução de trevo branco e trevo vermelho à partir de 1991. Foram aplicadas de 2 a 3 t.ha ${ }^{-1}$ de calcário dolomítico na superfície da pastagem, sem revolvimento do solo, a cada quatro a cinco anos, e realizadas adubações anuais de manutenção com $200 \mathrm{~kg} \cdot \mathrm{ha}^{-1}$ das fórmulas 10-30-10 ou 5-30-15. De 1995 a 1997, a adubação de manutenção foi reduzida a $100 \mathrm{~kg} \cdot \mathrm{ha}^{-1}$ ano $^{-1}$ da fórmula 5-30-15.

Nos tratamentos sem queima, o pastejo foi o rotativo, baseado na oferta de forragem, com o período de pastejo variável em função da massa de forragem disponível. A área do tratamento queimado permaneceu com lotação contínua durante todo o ano, e entre o final do inverno e início da primavera, 
a cada dois anos, o campo foi queimado. A queima foi feita a cada dois anos no final do inverno, e durante o ano de avaliação a área não foi queimada.

Os sítios escolhidos foram de $10 \times 30 \mathrm{~m}$, situados topograficamente numa encosta de cada potreiro, cuja situação foi a mais representativa do relevo da região. Em cada sítio foram locadas três gaiolas de exclusão ao pastejo.

A avaliação da vegetação ocorreu de setembro/1997 a setembro/1998, e as amostras foram coletadas dentro de gaiolas de exclusão ao pastejo. As gaiolas foram removidas para um novo local, representativo da condição do sítio a cada início de estação, após emparelhamento da vegetação onde as gaiolas seriam locadas. $\mathrm{O}$ corte de emparelhamento foi feito a uma altura de $5 \mathrm{~cm}$ acima do nível do solo, sendo o material cortado removido da área. Após o corte em cada gaiola, foi recolhido o material morto desprendido das plantas, junto à superfície do solo, o qual foi denominado mantilho. O material cortado foi colhido de um quadrado de $0,25 \mathrm{~m}^{2}$, acondicionado em sacos de polietileno, e seco em estufa até peso constante. Ao material morto juntou-se o material senescente (MSEN) ligado a planta, separado da amostra da pastagem e já seco. Os teores de $\mathrm{N}, \mathrm{P}, \mathrm{K}, \mathrm{Ca}$ e $\mathrm{Mg}$ nas amostras secas e moídas do mantilho acrescido do material senescente foram determinados através dos métodos de rotina do Laboratório de Análises de Solo e de Tecido Vegetal da Faculdade de Agronomia da UFRGS (TEDESCO et al., 1995). O percentual de cada nutriente na estação foi multiplicado pela quantidade de mantilho + MSEN acumulada em cada estação, obtendo-se a quantidade de nutrientes acumulados no mantilho + MSEN.

A metodologia estatística incluiu análise de variância, e as diferenças e/ou interações significativas em nível de $5 \%$ de probabilidade de erro ensejaram a aplicação do teste de WallerDuncan para os efeitos principais e o teste $\mathrm{t}$ de Student para as interações.

\section{RESULTADOS E DISCUSSÃO}

Houve efeito significativo de tratamento sobre os teores de nutrientes no mantilho + MSEN para todos os elementos avaliados, como pode ser observado na figura 1. Para $\mathrm{N}$ e $\mathrm{K}$, os teores são maiores no CNM e inferiores no tratamento SQSR e queimado, que não diferiram entre si.

$\mathrm{O}$ teor de $\mathrm{N}$ variou, em média, de 0,60 a $1,30 \%$ (Figura 1a), conforme tratamento e estação do ano, e está dentro da amplitude observada por ESTIVALET (1997) de 0,11 e 1,15\% de N no MM. Embora sem efeito de época, os teores de $\mathrm{N}$ nesta fração tendem a ser inferiores no verão. Dentre os nutrientes analisados por ESTIVALET (1997) nos tecidos mortos, o $\mathrm{N}$ foi o único elemento que apresentou tendência de redução em pastagem queimada. $\mathrm{O}$ teor de $\mathrm{N}$ na forragem do CNM tendeu a manter-se superior aos demais tratamentos ao longo de todo o ano, refletindo o melhor nível de fertilidade do solo.

Para o teor de $\mathrm{P}$, houve interação entre tratamentos e estações do ano. Conforme a Figura $1 \mathrm{~b}$, para os tratamentos queimado e SQSR, os teores de P não diferem entre estações, com valor médio de 0,065\%; já no CNM, foram inferiores no inverno em relação às demais épocas. Os níveis de $\mathrm{P}$ no CNM foram aproximadamente o dobro em relação às áreas sem melhoramento, à exceção do inverno em que não houve diferença significativa entre tratamentos. Provavelmente, devido à menor velocidade de crescimento e mineralização dos resíduos vegetais durante a estação fria, a palha permanece mais tempo na superfície do solo e, por isso, sofre lavagem de nutrientes. Isso contribuiu para uma queda acentuada nos níveis de $\mathrm{P}$ do tratamento CNM durante o inverno, os quais se mantiveram elevados durante o restante do ano.

O comportamento do $\mathrm{P}$ nos tecidos mortos reflete os níveis de $\mathrm{P}$ no solo, que dependem da adubação, do retorno de restos vegetais, das taxas de mineralização e das condições ambientais. Os teores de $0,09 \%$ de $\mathrm{P}$ no material senescente, observados por ESTIVALET (1997), são maiores do que os verificados aqui em pastagem nativa sem adubação (SQSR e queimada).

Para o teor de K no mantilho + MSEN, houve efeito de estação do ano, com teores médios entre tratamentos maiores na primavera $(0,35 \%)$, seguidos do verão $(0,27 \%)$, outono e inverno $(0,22 \%)$ (Figura 1c). Os teores de $\mathrm{K}$ nos tecidos mortos foram mais elevados, ao longo de todas estações, na pastagem melhorada em relação aos demais tratamentos.

Os níveis de $\mathrm{Ca}$ e $\mathrm{Mg}$ no mantilho + MSEN diferenciam-se em todos tratamentos $(\mathrm{P}<0,05)$, tendo sido maiores no $\mathrm{CNM}$, intermediários no SQSR e inferiores no queimado. Conforme observou ESTIVALET (1997), os níveis de $\mathrm{Ca}$ no material senescente foram maiores na primavera $(0,58 \%)$ e semelhantes no verão e outono (média de $0,54 \%$ ), enquanto o teor de $\mathrm{Mg}$ foi em média de $0,26 \%$ entre estações. Esses valores de $\mathrm{Ca}$ e $\mathrm{Mg}$ são superiores aos observados no presente estudo, em pastagem natural sem melhoramento.

Os níveis de $\mathrm{N}$, Ca e Mg no CNM tendem a ser maiores no outono. Por outro lado, observou-se tendência de redução desses níveis durante o verão e 
a) Nitrogênio

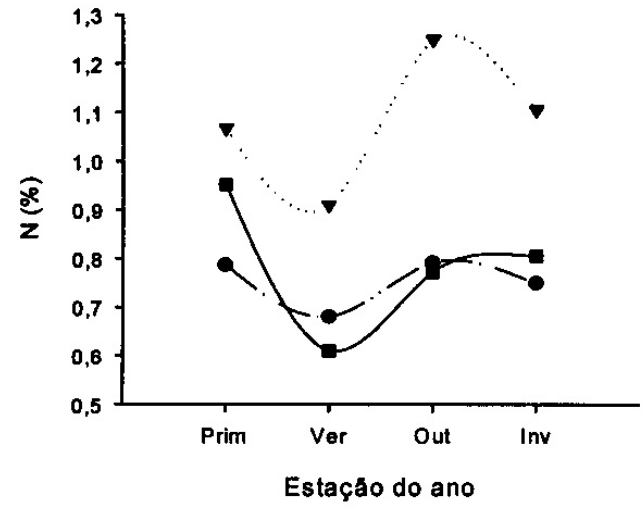

c) Potássio

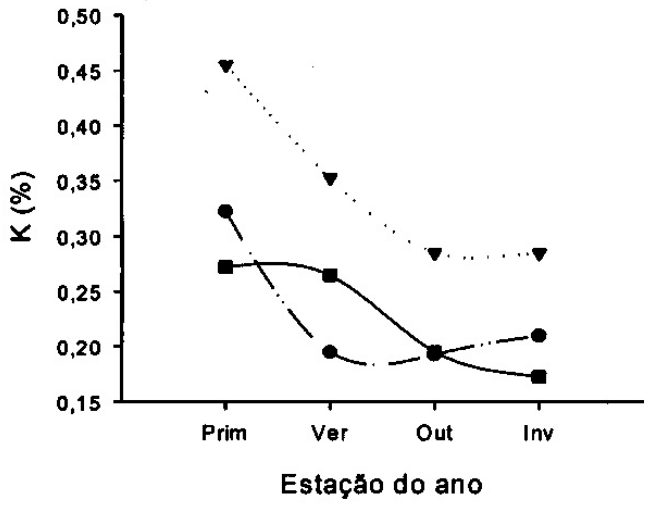

d) Cálcio

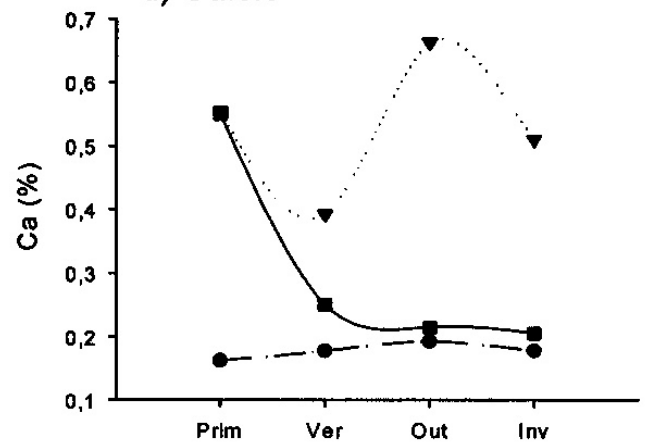

b) Fósforo

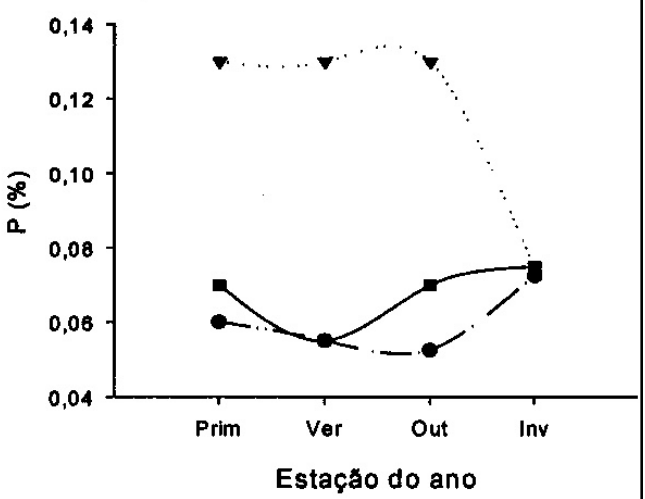

$\rightarrow-$ Sem queima s/roçada

Melh. 7 anos

$\rightarrow$ - Queima + 100 anos

Figura 1 - Teor de nitrogênio (a), fósforo (b), potássio (c), cálcio (d) e magnésio (e) na matéria seca do mantilho + MSEN empastagem natural sob distintos manejos. (André da Rocha, 1997/1998).

inverno. As espécies introduzidas na pastagem natural melhorada, bem como a adubação devem ter contribuído para mobilização de nutrientes no mantilho no outono. No verão, o alto volume de precipitação, em torno de $621 \mathrm{~mm}$, pode ter induzido a lavagem de nutrientes do mantilho + MSEN, ao passo que, no inverno, as baixas temperaturas determinam lenta taxa de produção e ciclagem do material senescente.
$\mathrm{Na}$ figura 2, são apresentadas as quantidades médias estacionais de nutrientes acumulados no mantilho + MSEN. Houve interação entre tratamentos e estações para a quantidade média estacional de $\mathrm{N}$ acumulado nos tecidos senescentes. A quantidade acumulada de $\mathrm{N}$ na primavera no tratamento SQSR $\left(54,07 \mathrm{~kg} \cdot \mathrm{ha}^{-1}\right)$ foi aproximadamente nove vezes superior à acumulada no queimado $\left(5,92 \mathrm{~kg} \cdot \mathrm{ha}^{-1}\right)$ e mais que o dobro em relação ao

Ciência Rural, v. 32, n. 5, 2002. 
a) Nitrogênio

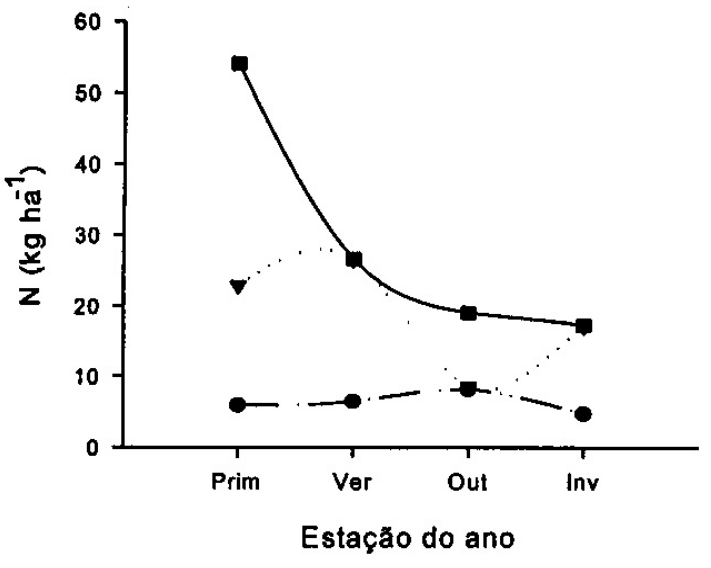

c) Potássio

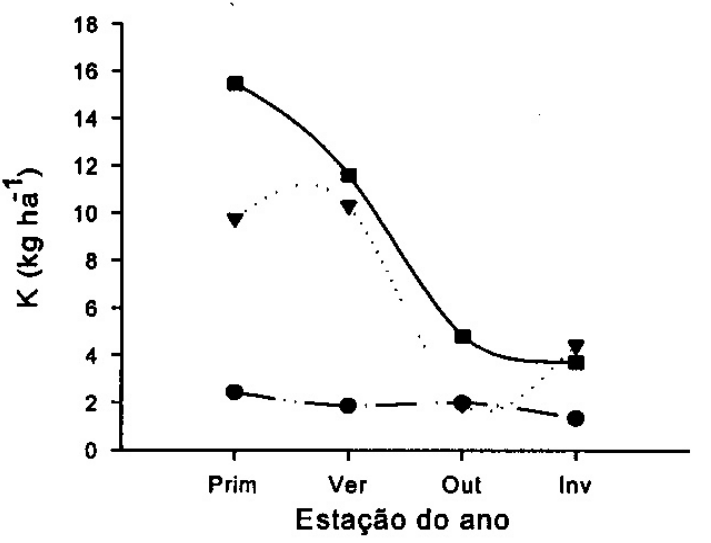

d) Cálcio

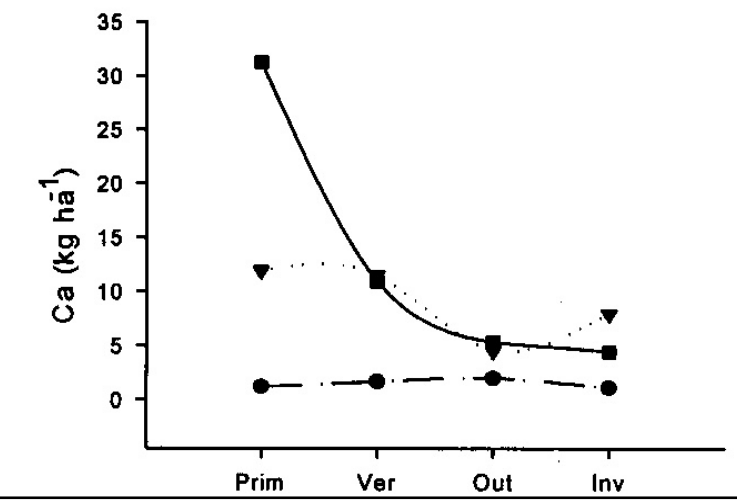

b) Fósforo

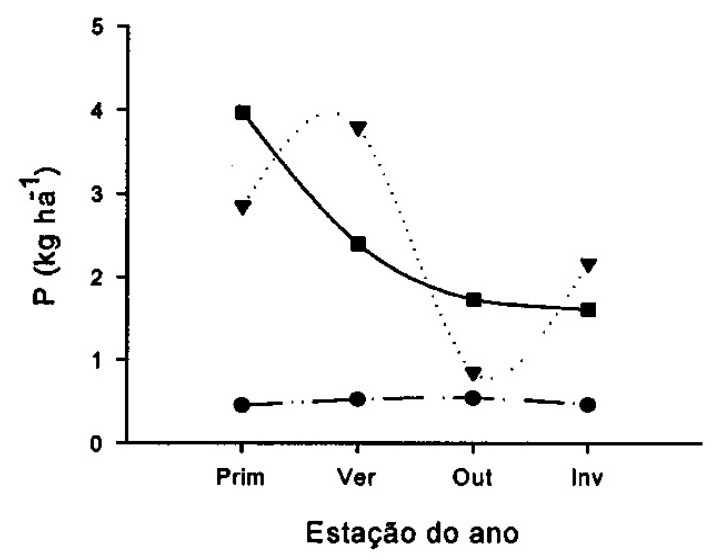

$\rightarrow-$ Sem queima s/roçada

..... Melh. 7 anos

$\rightarrow$ - Queima + 100 anos e) Magnésio

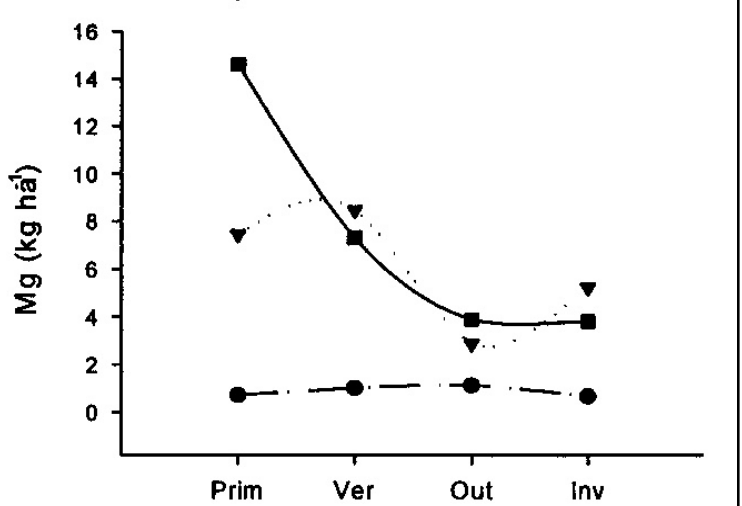

Figura 2 - Quantidade de nitrogênio (a), fósforo (b), potássio (c), cálcio (d) e magnésio (e) acumulados na matéria seca do mantilho + MSEN de uma pastagem natural sob distintos manejos. (André da Rocha, 1997/1998).

CNM (22,93kg.ha-1). Isso se deve ao volume de mantilho + MSEN acumulado no tratamento SQSR e, provavelmente, à sua lenta taxa de mineralização. No verão, o acúmulo de $\mathrm{N}$ foi maior nos tratamentos SQSR e no CNM $\left(26,64 \mathrm{~kg} \mathrm{ha}^{-1}\right)$ e inferior no queimado $\left(6,50 \mathrm{~kg} \cdot \mathrm{ha}^{-1}\right)$. Não houve diferença entre tratamentos nas demais épocas.

A área queimada apresentou acúmulo de $\mathrm{N}$ semelhante entre estações, enquanto no tratamento SQSR foi maior na primavera, e no CNM foi

Ciência Rural, v. 32, n. 5, 2002. 
inferior no outono, não diferindo nas demais épocas. ESTIVALET (1997) observou uma disponibilidade média de $\mathrm{N}$ de $29,5 \mathrm{~kg} \cdot \mathrm{ha}^{-1}$ no material morto do tratamento queimado, e de $76 \mathrm{~kg} \cdot \mathrm{ha}^{-1}$ na testemunha, a qual chega a $109 \mathrm{~kg}$ de N.ha ${ }^{-1}$ no outono, em função da exclusão ao pastejo e da quantidade acumulada de matéria seca da primavera até o outono. Segundo este autor, a menor quantidade de nutrientes no mantilho de área queimada pode ser explicada pelas perdas de matéria seca por combustão.

A quantidade média estacional de $\mathrm{P}$ acumulado no mantilho + MSEN foi afetada apenas por tratamento, sendo em média de $2,43 \mathrm{~kg} \cdot \mathrm{ha}^{-1}$ no tratamento SQSR e no CNM, e de $0,49 \mathrm{~kg} \cdot \mathrm{ha}^{-1}$ no queimado. Na Depressão Central do RS, (ESTIVALET, 1997) registrou-se uma disponibilidade média de $\mathrm{P}$ de 2,2; 4,3; 4,5 e $7,1 \mathrm{~kg} \mathrm{ha}^{-1}$, respectivamente, no material morto de pastagem sob queima, ceifa, diferimento e testemunha, também apontando valores inferiores para área queimada.

Para acúmulo de K no mantilho + MSEN, houve efeito simples de tratamentos, não diferindo entre SQSR e CNM, com média de 8,9 e 6,6 kg.ha ${ }^{-1}$, respectivamente, tendo sido inferior no queimado, com 1,9kg.ha- ${ }^{-1}$. ESTIVALET (1997) verificou um acúmulo de $\mathrm{K}$ de $13,5 \mathrm{~kg} \cdot \mathrm{ha}^{-1}$ no material morto da área queimada e de $43,7 \mathrm{~kg} \cdot \mathrm{ha}^{-1}$ na área sem queima e excluída do pastejo.

Houve interação entre tratamento e época para o acúmulo de $\mathrm{Ca}$ no mantilho + MSEN. Na primavera, o acúmulo de Ca foi superior no SQSR $\left(31,23 \mathrm{~kg} \cdot \mathrm{ha}^{-1}\right)$, seguido do CNM $\left(11,92 \mathrm{~kg} \cdot \mathrm{ha}^{-1}\right)$ e queimado $\left(1,22 \mathrm{~kg} \mathrm{ha}^{-1}\right)$, conforme mostra a figura $2 d$. No verão, não houve diferença entre SQSR e o CNM, com média de $11,2 \mathrm{~kg} \cdot \mathrm{ha}^{-1}$, mas foi menor no queimado, com 1,7kg.ha ${ }^{-1}$. Durante a estação fria, os tratamentos não diferiram entre si. $\mathrm{O}$ acúmulo de $\mathrm{Ca}$ na área SQSR foi superior na primavera e, no CNM, foi maior durante a estação quente, enquanto que para o tratamento queimado não houve diferença entre estações do ano. Também para tecido morto, ESTIVALET (1997) registra uma disponibilidade de Ca inferior na área queimada $\left(16,2 \mathrm{~kg} \cdot \mathrm{ha}^{-1}\right)$, variando nos demais tratamentos entre 21,9 e $42,0 \mathrm{~kg} \cdot \mathrm{ha}^{-1}$.

Quanto ao acúmulo de $\mathrm{Mg}$ no mantilho + MSEN, também houve interação de tratamento com relação à época. Na primavera, o acúmulo foi maior no tratamento SQSR $\left(14,6 \mathrm{~kg} \cdot \mathrm{ha}^{-1}\right)$, intermediário no CNM $\left(7,5 \mathrm{~kg} \mathrm{ha}^{-1}\right)$ e inferior no queimado $\left(0,7 \mathrm{~kg}^{-h^{-1}}\right)$ (Figura 2e). No verão, os tratamentos SQSR e CNM não diferiram $\left(7,9 \mathrm{~kg} \cdot \mathrm{ha}^{-1}\right)$ e foram superiores ao queimado $\left(1,0 \mathrm{~kg} \cdot \mathrm{ha}^{-1}\right)$. No outono, o acúmulo de $\mathrm{Mg}$ não diferiu entre tratamentos, enquanto no inverno foi maior no sistema CNM $\left(5,2 \mathrm{~kg} \cdot \mathrm{ha}^{-1}\right)$, inferior no queimado $\left(0,7 \mathrm{~kg} \cdot \mathrm{ha}^{-1}\right)$, ao passo que o tratamento SQSR não diferiu destes $\left(3,8 \mathrm{~kg} \cdot \mathrm{ha}^{-1}\right)$. Na área queimada, o acúmulo foi similar entre estações. Foi maior na primavera e no verão no $\mathrm{CNM}$; já, no SQSR, foi superior na primavera em relação às demais épocas. ESTIVALET (1997) reporta quantidades médias disponíveis de Mg no MS de $8,4 \mathrm{~kg} \cdot \mathrm{ha}^{-1}$ para área queimada e de $13,0 \mathrm{~kg} \cdot \mathrm{ha}^{-1}$ para os demais tratamentos.

A maior quantidade de nutrientes minerais disponíveis no material morto encontrada por ESTIVALET (1997) deve-se, principalmente, à diferente metodologia de amostragem da vegetação, em pastagens excluídas do pastejo e com corte feito rente ao solo. Neste sentido, a dinâmica da matéria orgânica e a ciclagem de nutrientes nos sistemas com pastagens podem ser significativamente diferentes, caso se efetue o pastejo com animais, por seus efeitos tanto diretos nos tipos de resíduos, como indiretos sobre a distribuição de dejeções e pisoteio (ROSSELLO, 1992).

No mantilho, o acúmulo de nutrientes foi proporcionalmente menor na área queimada em relação aos demais tratamentos sem queima, equivalendo a $26 \%$ do N, $20 \%$ do P, $24 \%$ do K, $14 \%$ do $\mathrm{Ca}$ e $13 \%$ do $\mathrm{Mg}$ acumulado naqueles tratamentos. O contínuo processo de queima está definindo o padrão de quantidade de nutrientes no mantilho, que está intimamente relacionado à produção de forragem.

As produções de matéria seca da forragem verde nos tratamentos SQSR, CNM e queimado foram, respectivamente, de 9555,9148 e $3665 \mathrm{~kg} \cdot \mathrm{ha}^{-1}$ ano $^{-1}$. Verifica-se a grande reserva de nutrientes que apresenta o mantilho + MSEN do tratamento SQSR (Figura2) que, mesmo sem entrada externa de nutrientes, possui potencial de produção de forragem semelhante ao sistema melhorado. Na área queimada e com pastejo contínuo, a remoção de tecidos vegetais é mais intensa, sendo que também a distribuição das excreções dos animais é mais desuniforme, interferindo na produção de forragem e no retorno de material senescente.

Em relação às quantidades de nutrientes retornados ao solo via mantilho + MSEN, percebe-se que existiu um ajuste do crescimento em relação ao meio nutricional disponível. Este fato é conhecido na nutrição mineral, no caso de plantas submetidas à estresse. GRIME (1979) comenta que plantas que se desenvolvem em locais sob intenso e freqüente distúrbio apresentam ampla plasticidade morfofisiológica, fazendo ajustes bioquímicos de membranas e organelas para suportar melhor as limitações do meio. Observações semelhantes foram feitas por KNAPP (1985) e STEUTER \& McPHERSON (1995). 
Embora as mudanças nas características do solo sejam muito lentas, a exposição de solo descoberto após a queimada e o menor retorno de mantilho + MSEN devem reduzir a fertilidade do solo e comprometer a produção vegetal da área, conforme já observado (HERINGER, 2000). Possivelmente, as perturbações no solo não são somente de ordem química, podendo haver interação entre os componentes físicos e biológicos num grau ainda não bem estudado e avaliado, mas capaz de resultar em expressivos incrementos de produtividade das áreas poupadas dos efeitos do fogo, como ocorreu no presente trabalho.

\section{CONCLUSÕES}

Sob o ponto de vista da preservação ecológica e produtiva de um sistema de produção da pastagem natural, a prática das queimadas deve ser evitada, pois ela reduz os teores de nutrientes no mantilho e no material senescente, assim como reduz a quantidade dos nutrientes, que retornam ao solo via material morto.

\section{REFERÊNCIAS BIBLIOGRÁFICAS}

BAETHGEN, W.E. Dinamica del nitrogeno en sistemas de rotacion cultivos-pasturas. Revista INIA de Investigaciones Agronomicas, Montevideo, v.1, n.1, p.3-25, 1992.

DERNER, J.D., BRISKE, D.D., BOUTTON, T.W. Does grazing mediate soil carbon and nitrogen accumulation beneath $\mathrm{C} 4$, perennial grasses along an environmental gradient? Plant and Soil, The Hague, v.149, p.147-156, 1997.

ESTIVALET, C.N.O. Efeitos da ceifa, queima e diferimento sobre a disponibilidade e composição botânica de uma pastagem natural. Porto Alegre, 1997. 97p. Dissertação (Mestrado em Zootecnia) - Programa de Pós-graduação em Zootecnia, Universidade Federal do Rio Grande do Sul, 1997.

GRIME, J.P. Plant strategies and vegetation processes. Chichester: John Wiley, 1979. 203p.
HERINGER, I. Efeitos do fogo por longo período e de alternativas de manejo sobre o solo e a vegetação de uma pastagem natural. Porto Alegre, 2000. 192p. Tese (Doutorado em Zootecnia) - Programa de Pós-graduação em Zootecnia, Universidade Federal do Rio Grande do Sul, 2000 .

KNAPP, A.K. Effect of fire and drought on the ecophysiology of Andropogon gerardii and Panicum virgatum in a tallgrass prairie. Ecology, Washington, v.66, n.4, p.1309-1320, 1985.

LEY, R.E., D'ANTONIO, C.M. Exotic grass invasion alters rates of $\mathrm{N}$ fixation in Hawaiian woodlands. Oecologia, Berlin, v.113, p.179-187, 1998.

MARY, B., RECOUS, S., DARWIS, D., et al. Interactions between decomposition of plant residues and nitrogen cycling in soil. Plant and Soil, The Hague, v.181, p.71-82, 1996.

PEARSON, C.J.; ISON, R.L. Agronomia de los sistemas pastoriles. Buenos Aires : Hemisferio Sur, 1994. 157p.

ROSSELLO, R.D. Evolucion de la materia organica en rotaciones de cultivos com pasturas. Revista INIA de Investigaciones Agronomicas, Montevideo, v.1, n.1, p.103-110, 1992.

RUSSELLE, M.P. Nutrient cycling in pasture. In: GOMIDE, J.A. (Ed.). SIMPÓSIO INTERNACIONAL SOBRE PRODUÇÃO ANIMAL EM PASTEJO, 1997, Viçosa. Anais... Viçosa : UFV, 1997. p.235-266.

SACIDO, M., CAUHÉPÉ, M. Calidade de los rebrotes postquema en pajonales de Paspalum quadrifarium. In: REUNIÓN DEL GRUPO TÉCNICO REGIONAL DEL CONO SUR EN MEJORAMIENTO Y UTILIZACION DE LOS RECURSOS FORRAJEROS DEL AREA TROPICAL Y SUBTROPICAL: GRUPO CAMPOS. 24, 1998, Montevideo. Anais... Montevideo : INIA, 1998. p.73-85. (Série Técnica n. 94).

STEUTER, A.A., Mc PHERSON, G.R. Fire as a physical stress. In: BEDUNAH, D.J., SOSEBEE, R.E. Wildland plants physiological ecology and developmental morphology. Denver: Society for Range Management, 1995. p.550-579.

TEDESCO, M.J., GIANELLO, C., BISSANI, C.A., et al. Análise de solo, plantas e outros materiais. 2.ed. Porto Alegre : Faculdade de Agronomia da UFRGS, 1995. 174p. (Boletim Técnico de Solos, 5).

TRACY, B.F., FRANK, D.A. Herbivore influence on soil microbial biomass and nitrogen mineralization in a northern grassland ecosystem: Yellowstone National Park. Oecologia Berlin, v.114, p.556-562, 1998. 